E3S Web of Conferences 1, 23003 (2013)

DOI: $10.1051 / \mathrm{e} 3$ sconf/20130123003

(C) Owned by the authors, published by EDP Sciences, 2013

\title{
A First Assessment of the Elemental Composition of Atmospheric Aerosols in the Canadian Oil Sands Region
}

\author{
E. Dabek-Zlotorzynska, V. Celo and D. Mathieu
}

Analysis and Air Quality Section, Air Quality Research Division, Atmospheric Science and Technology Directorate, Science and Technology Branch, Environment Canada, 335 River Road, Ottawa, Ontario, K1A 0H3, CANADA, ewa.dabek@ec.gc.ca

\begin{abstract}
Canadian Oil Sands, which comprise 97\% of Canada's 176 billion barrels of proven oil reserves, are located beneath $140,200 \mathrm{~km}^{2}$ of boreal forests, prairies and wetlands, and are the second largest known deposit of crude oil in the world. As such, this region has experienced rapid industrial development, which resulted also in increasing industrial air emissions, primarily from bitumen upgrading and mine vehicle fleet operations. This rapid development has led to concerns regarding health risk to humans, and other terrestrial and aquatic wildlife associated with exposure to toxic contaminants, especially metals and polycyclic aromatic compounds (PACs) particularly along the Athabasca River and its watershed. Canada's Minister of the Environment announced that Environment Canada (EC) will jointly lead, in collaboration with Government of Alberta and relevant stakeholders, the development and implementation of an enhanced monitoring system in the Oil Sands region to provide information on the state of the air, water, land and biodiversity. This work presents preliminary data on the first assessment of elemental composition of fine particulate matter (particles $<2.5 \mathrm{~mm}$ in diameter; $\mathrm{PM}_{2.5}$ ) at 3 air quality sites in close proximity to Oil Sands processing activities. Since December 2010, integrated 24 hour air samples were collected every sixth day on a 47-mm Teflon filters using Thermo Fisher Partisol 2000-FRM samplers operated by the National Air Pollution Surveillance (NAPS) network that involves EC and the Canadian provinces and territories. All samples including laboratory, travel and field blanks were subjected to gravimetric determination of $\mathrm{PM}_{2.5}$ mass and energy dispersive X-ray fluorescence (ED-XRF) analysis for 46 elements. Since ED-XRF is a non-destructive technique, $\mathrm{PM}_{2.5}$ samples were subsequently analyzed for 37 trace elements including rare earth elements using inductively-coupled plasma mass spectrometry (ICP-MS) combined with microwave-assisted acid digestion. The resulting data will be discussed.
\end{abstract}

Key words: atmospheric aerosols, metals, oil sands, assessment 